\title{
Inflammation and the absence of edema in the abdominal aortic aneurysm as determined by T2-weighted cardiovascular magnetic resonance imaging
}

\author{
J acob Budtz-Lilly ${ }^{1}$, Anders F. Mikkelsen ${ }^{2}$, Samuel A. Thrysøe ${ }^{2}$, William P. Paaske ${ }^{1}$, Won Yong \\ $\mathrm{Kim}^{3}$
}

1. Department of Cardiothoracic and Vasculary Surgery, Aarhus University Hospital Skejby, Denmark. 2. MR-center, Aarhus University Hospital Skejby, Denmark. 3. Department of Cardiology, Aarhus University Hospital Skejby, Denmark.

Correspondence: Jacob Budtz-Lilly. Address: Department of Cardiothoracic and Vascular Surgery T, Aarhus University Hospital, Skejby, Brendstrupgaardsvej 100, DK-8200 Aarhus N, Denmark. Email: jacoblilly@me.com.

Received: January 16, 2013

DOI : $10.5430 / j b g c . v 3 n 3 p 68$
Accepted: March 4, 2013

URL: http://dx.doi.org/10.5430/jbgc.v3n3p68

\section{Abstract}

Objective: The non-specific abdominal aortic aneurysm (AAA) is a local manifestation of a systemic disease, in which inflammation may play a role. This cardiovascular magnetic resonance (CMR) study utilizes a water-sensitive, T2weighted, short tau inversion recovery sequence (T2-STIR) to identify vessel wall edema as a marker for inflammation.

Methods: Twenty-two patients were included: 10 AAA patients, 10 healthy subjects, and two patients with known inflammation. MR T2-STIR images of aorta vessel wall and intraluminal thrombi were analyzed using OSIRIX software. Signal intensity values were normalized, and values from blinded and independent viewers were then averaged and analyzed using SPSS statistical software. The Kruskal-Wallis H test was used with post hoc analysis for differences of significance.

Results: Average AAA anterior-posterior diameter was $5.9 \pm 0.6 \mathrm{~cm}$ (range, 5.3-7.0cm). The Kruskal-Wallis $\mathrm{H}$ test revealed a significant difference between independent samples $(H(3)=20.36, P<.001)$. There was no significant difference in average intensities between AAA and healthy subjects $(P=.766)$.

Conclusion: This is the first study to examine edema in walls and thrombi of AAAs using T2-STIR imaging. No evidence of edema was identified in the aortic aneurysm wall, suggesting a lack of inflammatory activity.

\section{Key words}

Abdominal aortic aneurysm, Magnetic resonance imaging, Inflammation, STIR, Edema

\section{I ntroduction}

Evidence suggests that the formation of the non-specific abdominal aorta aneurysm (AAA) is a local representation of a systemic disease of the vasculature 1 and inflammation appears to play a role in the pathophysiological process ${ }^{[1]}$. In addition to the histological verification of heightened proteolytic activity and lymphocytic abundance, there is also 
evidence of systemic elevation of C-reactive protein (CRP), a response to inflammation, and cytokines in patients with AAAs ${ }^{[2-8]}$. Various imaging techniques have been used to visualize inflammatory changes within the aortic aneurysmatic wall and thereby potentially facilitate estimate of prognosis and response to medical treatment. Positron emission tomography/computed tomography (PET/CT), for example, has been utilized to investigate the uptake of 18F-fluorodeoxyglucose as a marker of increased metabolic activity within the aneurysmatic aortic wall, suggesting inflammation ${ }^{[9,10]}$. This approach has been hindered by the observation that at least half of all large arteries scanned show some degree of increased metabolic activity, despite no known vascular disease ${ }^{[11]}$. Cardiovascular magnetic resonance (CMR) technology is another diagnostic option, and one recent study points to the feasibility of CMR in conjunction with ultrasmall superparamagnetic iron oxide infusion in assessing inflammatory activity ${ }^{[12]}$.

The present study employs T2-weighted short tau inversion recovery CMR (T2-STIR CMR), which highlights hydrophilic tissue and reveals local edema, a marker of inflammation ${ }^{[13,14]}$. Identifying edematous changes has been shown to be beneficial in differentiating between chronic and active inflammation in spinal cord injuries ${ }^{[15]}$. It is sensitive enough to detect small vessel inflammation in the context of the acute coronary artery syndrome ${ }^{[16,17]}$. Finally, its use in identifying active aortic inflammation in Takayasu's arteritis has also recently been demonstrated ${ }^{[18]}$.

Based on these strengths, it was hypothesized that T2-STIR CMR should identify edema in a larger vascular structure, such as the aorta, provided it is present. The null hypothesis is thus, no edematous changes are identified in the AAA wall in comparison to otherwise healthy aortic tissue. The ramifications of findings could therefore help to clarify the role of inflammation in the AAA and perhaps affect decisions regarding treatment and prognosis.

\section{Materials and methods}

\subsection{Study design}

Twenty-two patients were included: 10 AAA patients, two patients with known inflammation of the aorta (an 18-year old woman with Takayasu's arteritis and a 69-year old woman with unspecificied aortitis), and ten healthy subjects with no known aortic pathology. Of the AAA patients, there were eight men and two women, and mean age was 71 (range 65-80 years). Each AAA patient was awaiting either surgical or endovascular treatment. All patients reached treatment, and no ruptures were reported. Average AAA anterior-posterior diameter was $5.9 \pm 0.6 \mathrm{~cm}$ (range 5.3-7.0 cm). All patients were receiving statin and antithrombocytic (either acetylsalicylic acid or clopidogrel) treatment (see Table 1). Approval from the regional ethics committee and written consent from each patient were obtained. Each patient underwent CMR imaging, utilizing the following protocol.

\subsection{I mage acquisition}

Patients were scanned in the supine position using a 1.5 T CMR scanner (Philips Medical Systems, Best, The Netherlands) equipped with a SENSE XL Torso 16 element phased array coil. Images were acquired using a peripheral pulse unit (PPU) gating, and a respiratory navigator was employed to allow for free-breathing acquisition. To selectively visualize edematous tissue, a fat-suppressive triple-inversion T2-weighted STIR sequence was employed covering the AAA in transverse slices using the following imaging variables: Repetition time (TR): 2 heart beats, echo time (TE): $70 \mathrm{ms,}$ inversion time (TI) for the inversion prepulse to null fat: $165 \mathrm{~ms}$, number of slices: 27, slice thickness: 4mm, inplane resolution $1.82 \times 2.28 \mathrm{~mm}^{2}$, number of signal averages (NSA): 3 . The echo train length was 15 , and two $40 \mathrm{~mm}$ saturation bands were imposed $10 \mathrm{~mm}$ above and below the aneurysm, respectively, to improve blood suppression.

The CMR images were coregistered with computed tomography (CT) scans for precise localisation of the vessel wall. The CT images were acquired using a Philips Brilliance 64-slice CT scanner (Philips, Best, The Netherlands), employing 100 $\mathrm{ml}$ of the omnipaque $350 \mathrm{mg}$ iodine/ml contrast agent in a standard clinical protocol. A total of 650 images were obtained with a slice thickness of $2 \mathrm{~mm}$ and an inplane resolution of $0.65 \times 0.65 \mathrm{~mm}^{2}$. 


\subsection{MR image analysis}

The T2-STIR CMR images were analyzed using OSIRIX imaging software (Pixmeo, Geneva, Switzerland). A region of interest was traced encompassing the aortic wall with the aid of both steady-state free precession (SSFP) images, as well as the CT scans. Signal intensity values were normalized to background signal from nearby muscular tissue. A similar procedure was performed for determining the average intensity of intraluminal thrombus. Two observers, blinded and independent of one another, carried out this process, and average signal intensities were then calculated.

The Kruskal-Wallis $\mathrm{H}$ test was utilized in order to compare the nonparametric data of the following four groups of tissue: AAA wall, AAA intraluminal thrombi, inflammatory aortic wall, and normal aortic vessel wall. Differences of significance were determined using the conventional $P$ value of 0.05 . Pairwise post hoc testing was carried out with adjusted levels of significant differences using the Bonferroni correction method. Statistics were performed on SPSS statistical software, version 20.0 .

Table 1. Data regarding the 22 subjects enrolled in the study

\begin{tabular}{cccccccc}
\hline Patient & Sex & $\begin{array}{l}\text { Age } \\
\text { (years) }\end{array}$ & $\begin{array}{l}\text { Aneurysm } \\
\text { diameter }(\mathbf{c m})\end{array}$ & $\begin{array}{l}\text { Open or endov- } \\
\text { ascular (EVAR) }\end{array}$ & $\begin{array}{l}\text { Prescribed } \\
\text { antithrombotic }\end{array}$ & $\begin{array}{l}\text { Prescribed } \\
\text { antistatin }\end{array}$ & $\begin{array}{l}\text { Smoking or } \\
\text { history thereof }\end{array}$ \\
\hline 1 & female & 76 & 5.4 & EVAR & Yes & Yes & Yes \\
2 & male & 70 & 5.5 & Open & Yes & Yes & Yes \\
3 & male & 63 & 5.3 & EVAR & Yes & Yes & Yes \\
4 & male & 72 & 6.0 & EVAR & Yes & Yes & Yes \\
5 & male & 72 & 6.1 & EVAR & Yes & Yes & Yes \\
6 & female & 65 & 7.0 & Open & Yes & Yes & Yes \\
7 & male & 80 & 7.0 & EVAR & Yes & Yes & Yes \\
8 & male & 77 & 6.0 & EVAR & Yes & Yes & Yes \\
9 & male & 65 & 5.5 & Open & Yes & Yes & Yes \\
10 & female & 74 & 5.6 & EVAR & Yes & Yes & Yes \\
Control & & & & & & & No \\
1 & male & 27 & 1.7 & -- & No & No & No \\
2 & male & 25 & 1.3 & -- & No & No & No \\
3 & male & 36 & 1.6 & -- & No & No & No \\
4 & male & 27 & 1.7 & -- & No & No & No \\
5 & female & 30 & 1.5 & -- & No & No & No \\
6 & male & 39 & 1.7 & -- & No & No & No \\
7 & male & 36 & 1.8 & -- & No & No & No \\
8 & female & 49 & 1.3 & -- & No & No & No \\
9 & male & 37 & 1.7 & -- & No & No & No \\
10 & male & 36 & 1.7 & -- & No & No & No \\
Takayasu's & female & 18 & n/a & -- & No & Yes & Yes \\
Aortitis & female & 69 & n/a & -- & Yes & &
\end{tabular}

\section{Results}

All patients completed the CMR examination, and all images were available for analysis. The normalized signal intensity values from T2-STIR CMR are reported in Table 2 and represented graphically in Figure 1. The Kruskal-Wallis $\mathrm{H}$ test revealed a significant difference between independent samples $(H(3)=20.36, P<.001)$. Mean ranks were as follows: 13.40 for AAA patients, 7.60 for healthy subjects, 26.00 for patients with known inflammation, and 24.71 for intraluminal thrombi. There was no significant difference in average intensities between AAA and healthy subjects (adjusted $P=.766$ ). Nor was there a significant difference between AAA and patients with known inflammatory disease (adjusted $P=.336$ ). There was a significant difference in signal intensity between intraluminal thrombi and the vessel wall of AAA patients 
(adjusted $P=.042$ ), as well as a significant difference between intraluminal thrombi and the vessel wall of healthy subjects (adjusted $P<.001$ ).

Table 2. Normalized and averaged MR-STIR intensity values.

\begin{tabular}{ccc}
\hline AAA Patient & Ratio Aorta Wall:Background Intensity & Ratio Thrombus: Background Intensity \\
\hline 1 & 1.13 & 3.13 \\
2 & 1.03 & --- \\
3 & 1.74 & 5.79 \\
4 & 1.89 & 4.02 \\
5 & 1.54 & 3.00 \\
6 & 1.62 & 8.22 \\
7 & 1.63 & --- \\
8 & 1.93 & --- \\
9 & 1.02 & 3.37 \\
10 & 1.33 & 2.20 \\
Control & & \\
1 & 1.01 & \\
2 & 0.79 & \\
3 & 1.57 & \\
4 & 1.17 & \\
5 & 1.24 & \\
6 & 1.12 & \\
7 & 1.40 & \\
8 & 0.95 & \\
9 & 0.93 & \\
10 & 1.49 & \\
Takayasu's & 3.75 &
\end{tabular}

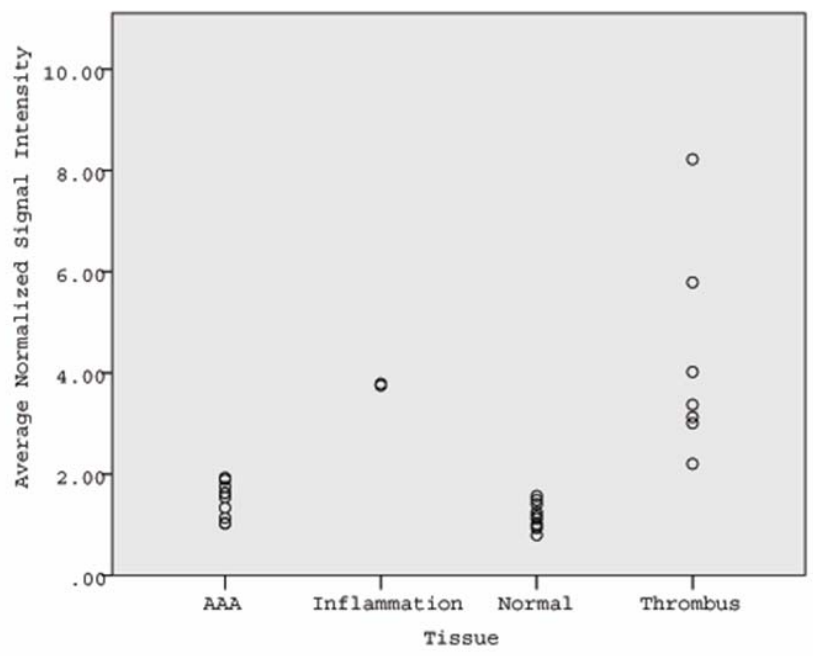

Figure 1. Dot-dot plots of the four groups of aorta tissue.

A representative CMR images from a patient with AAA can be seen in Figure 2. The intraluminal thrombus yields obvious enhancement, whereas the aortic wall itself remains dark, suggesting no edema or inflammation. 


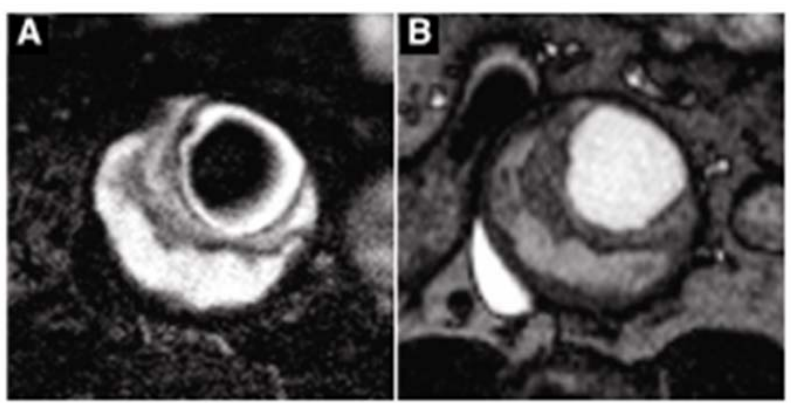

Figure 2. Cardiovascular magnetic resonance images from a 65-year old man with an abdominal aortic aneurysm measuring $7.0 \mathrm{~cm}$ in diamter. The T2-weighted short tau inversion recovery (STIR) sequence in 2A reveals little signal intensification and therefore little evidence of edema. Note the strong signal coming from the intraluminal thrombus. For orientation purposes and identification of the aortic wall, the steady-state free precession image is displayed in 2B.

\section{Discussion}

This is the first study to utilize T2-STIR CMR in the determination of edema in patients with abdominal aortic aneurysm. Edema, a reflection of vasodilation, dysfunctional intima, and subsequent attraction of leukocytes, inflammatory mediators, and water, is a sensitive indicator of the active process of inflammation. T2-STIR CMR takes advantage of this process and is a compelling diagnostic tool.

This study raises two issues. First, edema was not found in the aortic wall in patients with AAAs, specifically in those patients whose aneurysm meets the conventional maximum diameter criterion. In other words, the relative signal intensity of aortic vessel wall edema appears to be no greater than in healthy subjects with no known aorta pathology.

The lack of edema in the AAA wall suggests that there is no active inflammatory activity in the wall of an otherwise large aneurysm, which is in contrast to findings from previously reported ${ }^{[9,10]}$. This is not to say that chronic inflammation is not present, but the conspicuous absence of edema is suggestive. To some clinicians this may be a foregone conclusion, yet it is worth recalling that edema is otherwise readily evident in other active cardiovascular inflammatory states and reflects a degree of ongoing inflammatory activity. A recent study touched upon this issue of degrees, or changes, in inflammation, in the context of ruptured AAAs. The authors found that inflammatory markers such as T- and B-lymphocytes, as well as IL-6 and IL-1ß, did not increase or were not elevated in ruptured AAA tissue, in comparison to non-ruptured tissue ${ }^{[19]}$. That is, a chronic state of inflammation did not appear to change, despite the obvious acuity of vessel rupture. Combined with the present analysis, it would appear that it is not aortic wall inflammation that is driving the growth, and impending rupture, of an AAA.

The second issue raised above is the demonstration of high signal intensity by T2-STIR CMR within the intramural thrombus, which suggests fluid accumulation within and around the intramural thrombus and deserves greater attention. This fluid is often seen at open surgery, and it is perhaps not surprising that it contains water. It is worth reporting, however, that the entire thrombotic mass appears strongly edematous and, at any rate, suggests an active or evolving structure. Heightened proteolytic and inflammatory activity of the thrombus has previously been described ${ }^{\text {[20-23] }}$. The clinical importance of intramural thrombus has also received attention. One recent study relates the size of thrombi to the subsequent risk of cardiovascular events ${ }^{[24]}$. The possible high inflammatory activity of intraluminal thrombi, which the present study suggests, may therefore be related or associated with the overall systemic inflammation and deserves further investigation. 
One important methodological issue is the proximity of the aortic vessel wall and intramural thrombus, which is insufficiently addressed by studies utilizing PET-CT imaging. That is, much of the observed AAA inflammatory activity arises perhaps not from the vessel wall, but from the abutting thrombi, and imaging studies ought to be able to define this juxtaposition. Differentiation between the aortic wall and intraluminal thrombi is critical, and CMR, with the help of SSFP images, is adept at doing this.

Patients with inflamed aortas are relatively rare, yet two were included in this study, primarily to validate the ability of CMR to detect edema in the aorta even though it is known that CMR can detect inflammation at the coronary artery level $^{[16,17]}$.

One of the important limitations of the presented data is the confined perspective by which a single imaging sequence can provide. These images represent one single phase in the pathophysiologic state of AAA disease, and imaging at other clinical stages might reveal different, or evolving, evidence of edematous and inflammatory changes. As noted above, none of the patients went on to rupture, so there is no sense of how close to rupture their aneurysms were.

Another limitation is the absence of reported systemic levels of C-related protein (CRP). These have previously been shown to be elevated in AAA patients, but this may reflect the systemic response and not the process that is taking place at the AAA wall and thrombus level ${ }^{[5,6]}$. Albeit interesting, they would not clarify the focal process as addressed here. Similarly, the use of statins in the AAA patient group may also affect the degree of systemic and local inflammation. The pleiotropic effects of statin therapy on aneurysm growth or inflammation are unsettled, although a recent meta-analysis suggests that there is a dampening effect ${ }^{[25]}$. Finally, it should also be mentioned that a negative finding that reveals no edema, and therefore no active inflammation, leaves open the possibility of a type II error. That all patients' aneurysms were unequivocal in their lack of edema, however, is compelling and therefore merits documentation.

The degenerative pathophysiologic process and the precise role of inflammation within a "systemic inflammatory process" deserve further clarification. An appealing conjecture from the above findings is that it is the intraluminal thrombi which propels or sustains the inflammation, while the aortic wall manifests a more chronic level of inflammation, or at least one in which the activity is low enough to minimize edematous changes.

\section{References}

[1] Nordon IM, Hinchliffe RJ, Loftus IM, Thompson MM. Pathophysiology and epidemiology of abdominal aortic aneurysms. Nat Rev Cardiol. 2011; 8: 92-102. PMid:21079638 http://dx.doi.org/10.1038/nrcardio.2010.180

[2] Busuttil RW, Abou-Zamzam AM, Machleder HI. Collagenase activity of the human aorta: A comparison of patients with and without abdominal aortic aneurysms. Arch Surg. 1980; 115: 1373-8. PMid:6254469 http://dx.doi.org/10.1001/archsurg.1980.01380110105016

[3] Koch AE, Haines GK, Rizzo RJ, Radosevich JA, Pope RM, Robinson PG, Pearce WH. Human abdominal aortic aneurysms. Immunophenotypic analysis suggesting an immune-mediated response. Am J Pathol. 1990; 137: 1199-213. PMid:1700620

[4] Freestone T, Turner RJ, Coady A, Higman DJ, Greenhalgh RM, Powell JT. Inflammation and matrix metalloproteinases in the enlarging abdominal aortic aneurysm. Arterioscler Thromb Vasc Biol. 1995; 15: 1145-51. PMid:7627708 http://dx.doi.org/10.1161/01.ATV.15.8.1145

[5] Juvonen J, Surcel HM, Satta J, Teppo AM, Bloigu A, Syrjala H, et al. Elevated circulating levels of inflammatory cytokines in patients with abdominal aortic aneurysm. Arterioscler Thromb Vasc Biol. 1997; 17: 2843-7. PMid:9409264 http://dx.doi.org/10.1161/01.ATV.17.11.2843

[6] Vainas T, Lubbers T, Stassen FR, Herngreen SB, van Dieijen-Visser MP, Bruggeman CA, et al. Serum C-reactive protein level is associated with abdominal aortic aneurysm size and may be produced by aneurysmal tissue. Circulation. 2003; 107: 1103-5. PMid:12615785 http://dx.doi.org/10.1161/01.CIR.0000059938.95404.92

[7] Brophy CM, Marks WH, Reilly JM, Tilson MD. Decreased tissue inhibitor of metallproteinases (TIMP) in abdominal aortic aneurysm tissue: a preliminary report. J Surg Res. 1991; 50: 653-7. http://dx.doi.org/10.1016/0022-4804(91)90058-T 
[8] Rasmussen TE, Hallett JW Jr, Schulte S, Harmsen WS, O'Fallon WM, Weyand CM. Genetic similarity in inflammatory and degenerative abdominal aortic aneurysms: a study of human leukocyte antigen class II disease risk genes. J Vasc Surg. 2001; 34: 84-9. PMid:11436079 http://dx.doi.org/10.1067/mva.2001.115603

[9] Reeps C, Essler M, Pelisek J, Seidl S, Eckstein HH, Krause BJ. Increased 18F-fluorodeoxy glucose uptake in abdominal aortic aneurysms in positron emission/computed tomography is associated with inflammation, aortic wall instability, and acute symptoms. J Vasc Surg. 2008; 48: 417-23. PMid:18572354 http://dx.doi.org/10.1016/j.jvs.2008.03.059

[10] Sakalihasan N, Van Damme H, Gomez P, Rigo P, Lapiere CM, Nusgens B, Limet R. Positron emission tomography (PET) evaluation of abdominal aortic aneurysm (AAA). Eur J Vasc Endovasc Surg. 2002; 23: 431-6. PMid:12027471 http://dx.doi.org/10.1053/ejvs.2002.1646

[11] Yun M, Jang S, Cucchiara A, Newberg A, Alavi A. 18F FDG uptake in the large arteries: a correlation study with the atherogenic risk factors. Semin Nucl Med. 2002; 32: 70-6. PMid:11839072 http://dx.doi.org/10.1053/snuc.2002.29279

[12] Sadat U, Taviani V, Patterson AJ, Young VE, Graves MJ, Teng Z, et al. Ultrasmall superparamagnetic iron oxide-enhanced magnetic resonance imaging of abdominal aortic aneurysms-a feasibility study. Eur J Vasc Endovasc Surg. 2011; 41: 167-74. PMid:20869889 http://dx.doi.org/10.1016/j.ejvs.2010.08.022

[13] Cohnheim J. Lectures in general pathology. London: New Sydenham Society, 1889.

[14] Onat D, Brillon D, Schmidt AM, Colombo PC. Human vascular endothelial cells: A model system for studying vascular inflammation in diabetes and atherosclerosis. Curr Diab Rep. 2011; 11: 193-202. PMid:21337131 http://dx.doi.org/10.1007/s11892-011-0182-2

[15] Weber U, Hodler J, Kubik RA, Rufibach K, Lambert RG, Kissling RO, Pfirrmann CW, Maksymowych WP. Sensitivity and specificity of spinal inflammatory lesions assessed by whole-body magnetic resonance imaging in patients with ankylosing spondylitis or recent-onset inflammatory back pain. Arthritis Rheum. 2009; 61: 900-8. PMid:19565558 http://dx.doi.org/10.1002/art.24507

[16] Pedersen SF, Thrysoe SA, Paaske WP, Thim T, Falk E, Ringgaard S, et al. Determination of edema in porcine coronary arteries by T2 weighted cardiac magnetic resonance. J Cardiovasc Magn Reson. 2011; 13: 52-9. PMid:21936914 http://dx.doi.org/10.1186/1532-429X-13-52

[17] Kim WY, Christiansen EH, Thrysoe SA, Al-Mashhadi RH, Botker HE, Bottcher M, Holm NR, Falk E. First in vivo demonstration of coronary edema in culprit lesion of patient with acute coronary syndrome by cardiovascular magnetic resonance. Circ Cardiovasc Imaging. 2011; 4: 344-6. PMid:21586745 http://dx.doi.org/10.1161/CIRCIMAGING.110.963074

[18] Budtz-Lilly JW, Paaske WP, Thrysoe SA, Andersen G. Takayasu's arteritis and the utility of magnetic resonance imaging. J Vasc Surg. 2012; 56: 832. PMid:22917045 http://dx.doi.org/10.1016/j.jvs.2011.04.050

[19] Wilson WR, Wills J, Furness PN, Thompson MM. Abdominal aortic aneurysm rupture is not associated with an up-regulation of inflammation within the aneurysm wall. Eur J Vasc Endovasc Surg. 2010; 40: 191-5. PMid:20537568 http://dx.doi.org/10.1016/j.ejvs.2010.04.014

[20] Kazi M, Thyberg J, Religa P. Influence of intraluminal thrombus on structural and cellular composition of abdominal aorticaneurysm wall. J Vasc Surg. 2003; 38: 1283-92. http://dx.doi.org/10.1016/S0741-5214(03)00791-2

[21] Stenbaek J, Kalin B, Swedenborg J. Growth of thrombus is a better predictor for rupture than diameter in patients with abdominal aortic aneurysms. Eur J Vasc Endovasc Surg. 2000; 20: 466-9. PMid:11112467 http://dx.doi.org/10.1053/ejvs.2000.1217

[22] Vorp DA, Lee PC, Wang DH, Makaroun MS, Nemoto EM, Ogawa S, et al. Association of intraluminal thrombus in abdominal aortic aneurysm with local hypoxia and wall weakening. J Vasc Surg. 2001; 34: 291-9. PMid:11496282 http://dx.doi.org/10.1067/mva.2001.114813

[23] Satta J, Laara E, Juvonen T. Intraluminal thrombus predicts rupture of an abdominal aortic aneurysm. J Vasc Surg. 1996; 23: 737-9. http://dx.doi.org/10.1016/S0741-5214(96)80062-0

[24] Parr A, McCann M, Bradshaw B, Shahzad A, Buttner P, Golledge J. Thrombus volume is associated with cardiovascular events and aneurysm growth in patients who have abdominal aortic aneurysms. J Vasc Surg. 2011; 53: 28-35. PMid:20934838 http://dx.doi.org/10.1016/j.jvs.2010.08.013

[25] Takagi H, Yamamoto H, Iwata K, Goto S, Umemoto T; for the ALICE (All-Literature Investigation of Cardiovascular Evidence) Group. Effects of Statin Therapy on Abdominal Aortic Aneurysm Growth: A Meta-analysis and Meta-regression of Observational Comparative Studies. Eur J Vasc Endovasc Surg. 2012; 44: 287-92. PMid:22824348 http://dx.doi.org/10.1016/j.ejvs.2012.06.021 